\title{
Projection in Hilbert Space for flood forecasting of the Pomahaka River, New Zealand
}

\author{
M. Mohssen \\ Department of Environmental Management, Lincoln University, \\ New Zealand
}

\begin{abstract}
A proper flood forecast of river flows can provide communities and/or governmental agencies with a quite effective tool for flood warning and in turn reducing/mitigating the negative impacts of incoming flood events. This research presents a new approach for flood forecasting of the Pomahaka River in Otago, New Zealand. This methodology is based on the projection in Hilbert Space of hourly flows of the Pomahaka River at Burkes Ford on the span of hourly rainfall data and/or previous flows of the same flow site or other flow sites. The projection theorem in Hilbert Space guarantees that the estimated parameters will produce a model with the least mean squared error. The Pomahaka catchment has rural aspects and its land use is mainly agricultural activities. The Pomahaka catchment is about $1871 \mathrm{~km}^{2}$, and has several flow and rainfall sites. Only 3 rainfall sites and 3 flow sites have been used in this research due to data availability. Hourly flows and rainfall data for this catchment have been investigated and 26 high flow events of the Pomahaka River at Burkes Ford, have been identified for the modelling process. A new model for simulating hydrologic abstractions have been developed and compared to the commonly used NRCS method. Results of the flood forecast modelling process, based on projection in Hilbert Space, for producing a $10 \mathrm{hr}$ forecast model for the Pomahaka River, achieved an overall value of 0.76 for $\mathrm{R}$ squared and 0.87 for Filliben correlation coefficient.
\end{abstract}

Keywords: flood forecast, Hilbert Space, rainfall-runoff modelling, Pomahaka catchment. 


\section{Introduction}

Floods are the most common natural disaster with the most costly damages in the world, and particularly in New Zealand where almost every year one or more regions are devastated by floods. About 935 devastating floods occurred during the period 1920 to 1983 in New Zealand [1], making it, on average, about 15 severe floods annually. The economic, social and environmental costs of these floods are usually tremendous, and the development of a new reliable forecast model, which is calibrated specifically for catchments of interest in New Zealand, can have a significant impact on providing reliable forecasts and reducing these costs and mitigating the negative impacts during and after these natural hazard events. Literature is rich in mathematical models for the purpose of flood forecasting [2-11]. However, due to the complexity and the high variability of the underlying hydrological processes, it is usually a challenge to forecast floods reliably for the shorter time step, such as hourly [12, 13]. Traditional watershed models usually require an experienced hydrologist to derive and apply them for a specific catchment, which might not be available during a flood event at the agency/organisation which requires their application for an imminent flood event. An easy to apply model, which is developed for a specific river catchment, can be used by public and private organisations to deliver a proper warning of an incoming event.

\section{Study area}

The Pomahaka Catchment (shown in Figure 1), lies in the South West of Otago region, New Zealand, in mainly agricultural area, with pasture grazing the dominant land use. It is a big catchment with a total area of $2067 \mathrm{~km}^{2}$, which is expected to have impact on the high variability of rainfall and in turn flows of the Pomahaka River tributaries within the catchment.

Figure 1 shows the available rainfall and flow sites for the Pomahaka Catchment. Several of these sites have started operation recently, and they have, relatively, few years of record. Thus, only four rainfall sites "Waikaia River at Piano Flat, Pomahaka at Moa Flat, Wendon Valley at Waikaka and Waipahi at The Cairn", and only three flow sites "Pomahaka at Glenken, Pomahaka at Burkes Ford, and Waipahi at Waipaha. Piano Flat and Moa Flat rainfall sites represent the northern part of the catchment area, Waikaka represents the middle, while The Carin represents the southern part. Moa Flat rainfall site is on higher elevation " $620 \mathrm{~m}$ ", while the other three rainfall sites range between 190 to $254 \mathrm{~m}$ amsl. This raises concern that, during some events depending on the season, precipitation at Moa flat could be snow, while it is rain in other sites.

Glenken flow site collects runoff from the northern area of the catchment $\left(711 \mathrm{~km}^{2}\right)$, while Waipahi flow site drains the southern catchment $\left(300 \mathrm{~km}^{2}\right)$, and both contribute to the flows at Burkes Ford, which has a catchment area of $1871 \mathrm{~km}^{2}$. Burkes Ford records the Pomahaka River flows before it drains to the Clutha River, the largest river "flow wise" in New Zealand. 


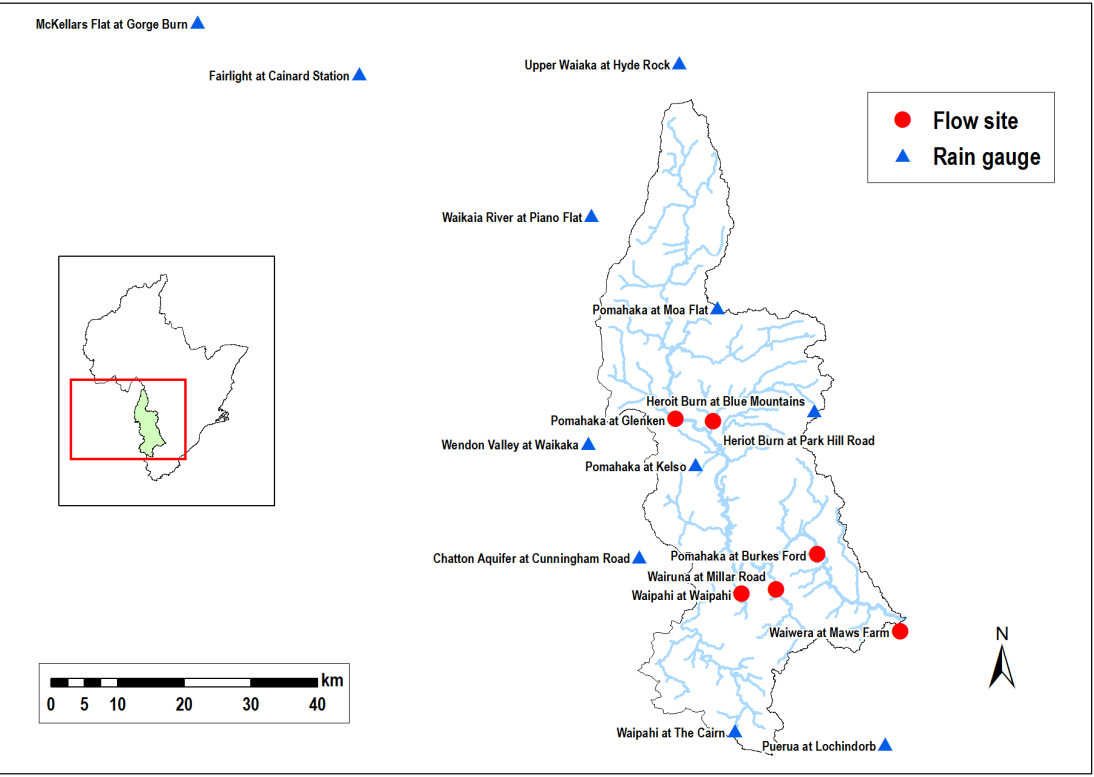

Figure 1: The Pomahaka catchment.

\section{Materials and methods}

\subsection{Rainfall and flow data}

To carry out this research study, 26 high flow events during the period 1996 to 2015 for the Pomahaka River at Burkes Ford have been identified and selected. Despite the availability of the Pomahaka River flows starting from 1961, other sites, especially Waipahi, limited the ability of collecting high flow events for a longer time span, see Table 1. Hourly flows and rainfall data for these events were collected from the Otago Regional Council, New Zealand. The choice of these events were based on being significantly high events, ability to select its "causing" rainfall and the availability of hourly data for the four rainfall and the three flow sites which were used in this study, as shown in Table 1. The maximum recorded flow at Burkes Ford is $1153.7 \mathrm{~m}^{3} / \mathrm{s}$, but this event occurred on 17 January 1980, outside the selected period which has available rainfall and flow data for all the seven sites under study. The maximum flow during the selected period (1996 to 2015) is $762 \mathrm{~m}^{3} / \mathrm{s}$, which is the maximum flow of the $14^{\text {th }}$ delected event and occurred on $7 / 02 / 2011$. The "lowest" high flow of the selected events is $124 \mathrm{~m}^{3} / \mathrm{s}$, of the $24^{\text {th }}$ event and occurred on $16 / 08 / 2015$. 
Table 1: $\quad$ Selected flow and rainfall sites of the Pomahaka catchment.

\begin{tabular}{|c|c|c|c|c|c|}
\hline Site & Type & Start date & Northing & Easting & Elev. $(\mathrm{m})$ \\
\hline $\begin{array}{c}\text { Pomahaka at Burkes } \\
\text { Ford }\end{array}$ & Flow & $4 / 08 / 1961$ & 1321680 & 4893100 & 40 \\
\hline $\begin{array}{c}\text { Pomahaka at } \\
\text { Glenken }\end{array}$ & Flow & $30 / 06 / 1992$ & 1300420 & 4913600 & 200 \\
\hline Waipahi at Waipahi & Flow & $4 / 07 / 1996$ & 1310330 & 4887180 & 112 \\
\hline $\begin{array}{c}\text { Waikaia River at } \\
\text { Piano Flat }\end{array}$ & Rain & $28 / 08 / 1977$ & 1287763 & 4944229 & 215 \\
\hline $\begin{array}{c}\text { Pomahaka at Moa } \\
\text { Flat }\end{array}$ & Rain & $1 / 01 / 1988$ & 1306670 & 4930220 & 620 \\
\hline $\begin{array}{c}\text { Wendon Valley at } \\
\text { Waikaka }\end{array}$ & Rain & $26 / 07 / 1988$ & 1287310 & 4909914 & 190 \\
\hline $\begin{array}{c}\text { Waipahi at } \\
\text { The Cairn }\end{array}$ & Rain & $10 / 04 / 1990$ & 1309280 & 4866650 & 254 \\
\hline
\end{tabular}

\subsection{Runoff estimation}

Analyses of the flow hydrographs at Burkes Ford for the selected events was carried out to estimate the runoff hydrograph for each event, by separating the base flow. As our concern in this study is with high flow events, it is expected that the impact of the methodology to "estimate" the base flow will not affect much the results, having in mind that the objective is to get the projection of the estimated runoff hydrograph on observed flows and rainfalls at other sites, and the same approach of base flow separation will be applied to all events. The approach applied was based on a combination of the straight line and the fixed base methods [14]. In this approach, "stable" flows before the start of the event were assumed to be the base flow, were extended until the time of the peak flow, then linearly connected to the flow after 150 hours from the peak, assuming that runoff contribution from this catchment ends after 150 hours from the peak flow. The choice of the 150 hours was based on the analysis of the flow hydrographs of the catchment at Burkes Ford. However, an obstacle to the choice of 150 hours was that several selected events lacked this time period after their peaks. This usually happened due to the occurrence of another event just after the event of concern, and flows started to be influenced by the rainfall of the oncoming event. Thus, extension of the recession limb of the flow hydrograph was required. Analysis of the recession part of the hydrographs indicated that the best mathematical formula to simulate it is as follows:

$$
\frac{Q_{t}}{Q_{t-1}}=a t^{b}
$$

where $Q_{t}$ is the "recession" flow at time $t$, starting 12 hours after the peak flow, a and $\mathrm{b}$ are parameters. For the flows at Burkes Ford, the estimated value for a was 0.937 , while it was 0.013 for b. Figure 2 shows the extended hydrograph, along with the estimated base flow for the 2nd event, which occurred in January 
1997. The extended hydrograph started from hour 161 from the start of the event. As this is a typical case for all other events, it shows that the derived approach will produce quite reliable estimates of the runoff of each event.

Total runoff volumes for all the 26 events were calculated from the flow hydrograph and the base flow, and areal precipitation over the whole catchment was estimated by Thiessen polygon method. Figure 3 presents the relationship

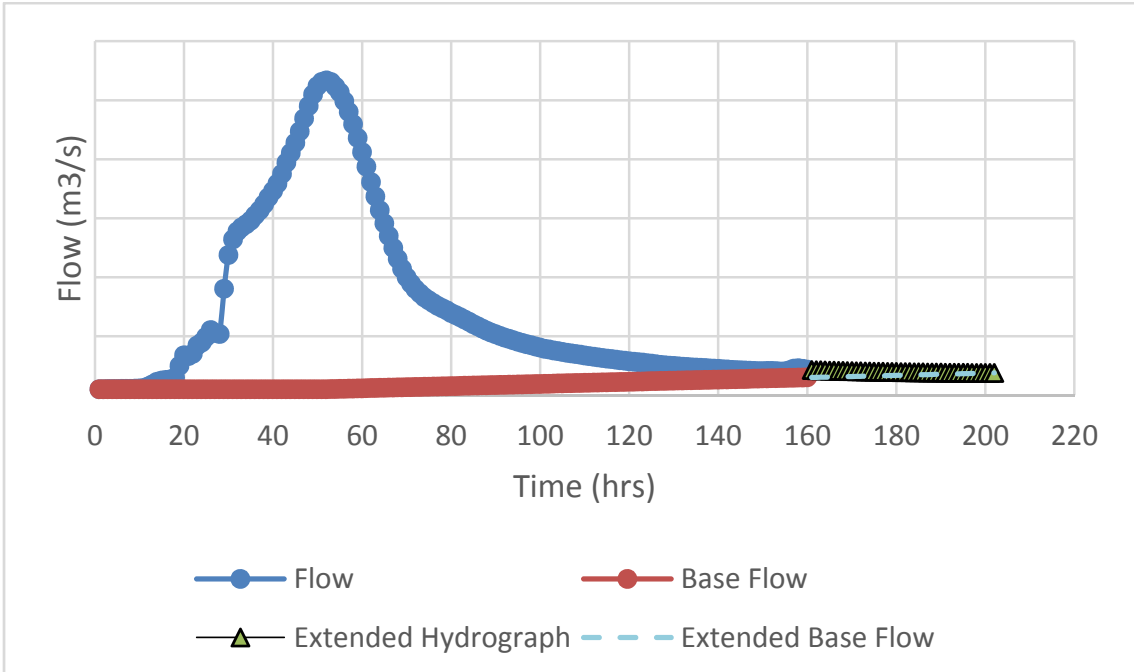

Figure 2: Extended hydrograph and estimated base flow for Event \# 2.

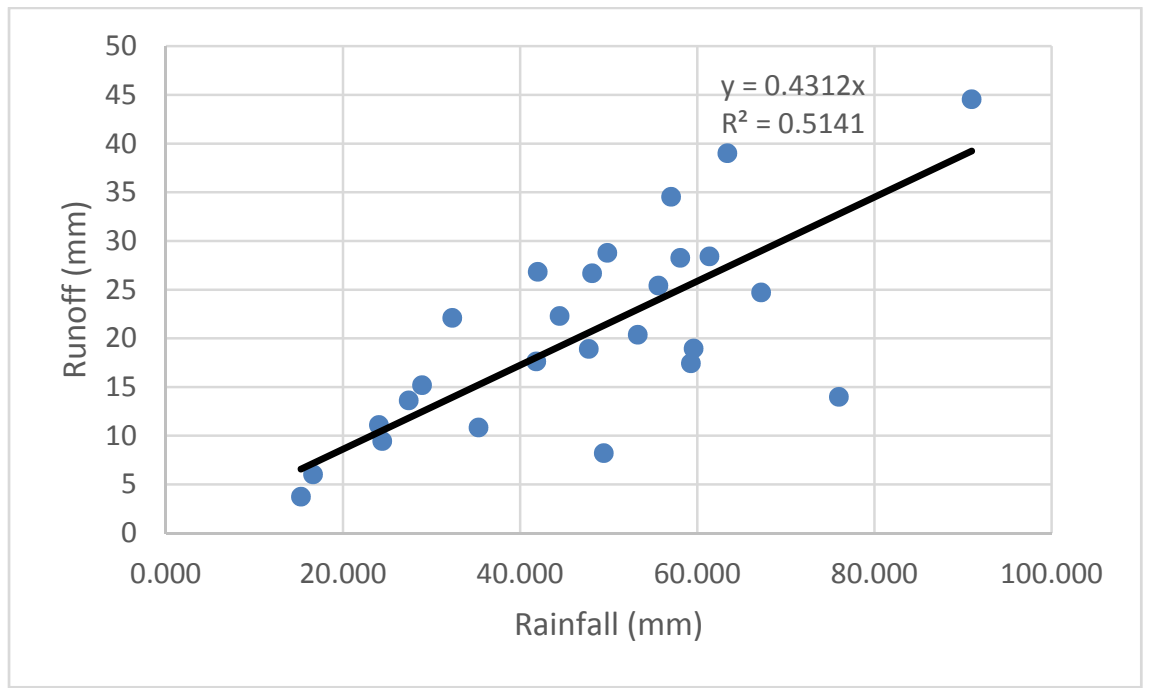

Figure 3: Relation between runoff and rainfall for the Pomahaka catchment at Burkes Ford. 
between total runoff and areal rainfall depth, which suggests a linear relationship as follows:

$$
\text { Runoff }=0.427 * \text { Rainfall }
$$

\subsection{Projection model}

Hilbert space is similar to our traditional Euclidean space (X, Y, Z coordinate system), but deals with random variables and probability spaces. After estimating the runoff hydrographs for high flow events, these flows are projected on the span of hourly rainfall data and/or previous flows of the same flow site or other flow sites. The projection theorem in Hilbert Space [15] guarantees that the estimated parameters will produce a model with the least mean square error. In Hilbert space, the following equation applies:

$$
<\mathrm{Q}-\hat{Q}, \mathrm{X}_{\mathrm{i}}>=\mathbf{0}
$$

where $<\mathrm{X}, \mathrm{Y}>=\mathrm{E}[\mathrm{XY}]$ in Hilbert Space, and the streamflow at time $\mathrm{t}$ " $\mathrm{Q}_{\mathrm{t}}$ " (noted here as Q) is considered an element of a Hilbert space $\mathrm{H}$, and other hydrologic variables, on which $\mathrm{Q}$ to be projected on, are considered to constitute a closed sub-space $\mathrm{S}$ of $\mathrm{H}$. These "other" hydrologic variables can be lagged flows $\mathrm{Q}_{\mathrm{i}, \mathrm{t}-\mathrm{L}}$ and rainfalls $\mathrm{R}_{\mathrm{i}, \mathrm{t}-\mathrm{L}}$ (noted here as $\mathrm{X}_{\mathrm{i}}$ ) at sites $\mathrm{i}, \mathrm{i}=1$ to $\mathrm{N}$, and lagged $\mathrm{L}$ hours before time $t$, where $L$ can range from zero to any integer value. The projection of $\mathrm{Q}$ in the sub-space $\mathrm{S}$ is denoted by $\hat{Q}$, where $\hat{Q} \in \mathrm{S}$. In Hilbert space, $<\mathrm{Q}-\hat{Q}$, $X_{i}>$ should equal zero for all $X_{i} \in S, i=1$ to $N$ to produce the predictor $\hat{Q}$ with the minimum least squared error. This is a consequence of $\mathrm{Q}-\hat{Q}$ being orthogonal to $\mathrm{X}_{\mathrm{i}}$. Due to the linearity of Hilbert space, this results in the following system of $\mathrm{N}$ equations:

$$
<\mathrm{Q}, \mathrm{X}_{\mathrm{i}}>=<\hat{Q}, \mathrm{X}_{\mathrm{i}}>\quad, \mathrm{i}=1 \text { to } \mathrm{N}
$$

$\hat{Q}$ can be a non-linear function of the "other" hydrologic variables $\mathrm{X}$, but in this application, the linear projection of $\mathrm{Q}$ on the span of $\mathrm{S}\left(\mathrm{X}_{\mathrm{i}}, \mathrm{i}=1\right.$ to $\left.\mathrm{N}\right)$ is used $\left(\hat{Q}=\sum_{i=1}^{N} \propto_{i} X_{i}\right)$. For this case, a system of $\mathrm{N}$ simultaneous linear equations are produced which are solved to obtain the corresponding coefficients for the "other" hydrologic variables $\mathrm{X}_{\mathrm{i}}, \mathrm{i}=1$ to $\mathrm{N}$.

\section{Results and discussion}

\subsection{Comparison between US NRCS and the developed approach for estimating Runoff}

Figure 4 shows a comparison between applying this approach to simulate the relationship between rainfall and runoff, and using the commonly applies US Natural Resources Conservation Service method (NRCS) [15]. It should be noted that the curve number $\mathrm{CN}$ for the NRCS formula was optimised to produce the minimum squared error, which means that this is the best the NRCS method can offer. 


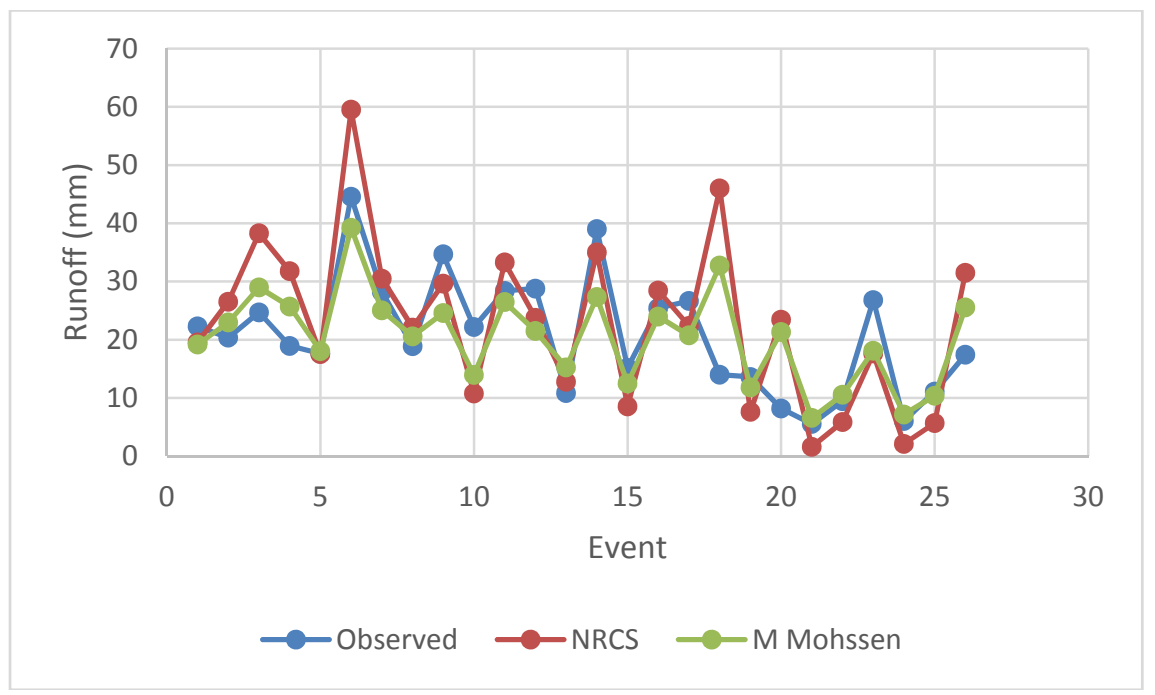

Figure 4: Runoff simulated by US NRCS method and M. Mohssen.

Despite the fact that the new approach is simpler than the US NRCS method, it is evident from Fig. 4 that it simulates better the total runoff from rainfall events. The total runoff for all events produced by this approach was $530 \mathrm{~mm}$, compared to an observed value of $539 \mathrm{~mm}$, while the US NRCS method produced a total runoff of $592 \mathrm{~mm}$. The squared error for this approach was $11.6 \mathrm{~m}^{3} / \mathrm{s}$, while it was $14 \mathrm{~m}^{3} / \mathrm{s}$ for the US NRCS method. It should be noted that Eq. (2) was developed specifically for the Pomahaka catchment.

\subsection{Flood forecast model for the Pomahaka River at Burkes Ford}

An analysis of lagged correlations between runoff flows and rainfalls and flows of other sites has been carried out to provide guidance on optimum lags between the projected flows and the other variables on which these flows are to be projected. The analysis suggested to lag rainfalls from 10 to 22 hours. This means that current rainfalls can be used to estimate the flow at Burkes Ford 10 hours later. Thus, for each of the rainfall sites, hourly rainfalls were lagged 10 hours, 11 hours,..., until 22 hours, while flows of Glenken and Waipahi were lagged only 10 hours. Thus, the forecast model will give 10 hours forecasts for the flows at Burkes Ford based on current hourly flows at Glenken and Waipahi, and current and previous hourly rainfalls at the rainfall sites. Out of the selected 26 high flow events, 24 were used for model calibration to estimate the models' parameters, and two events were used for the validation of the model to verify its ability to simulate events which were not included in its parameter estimation process. Figure 5 shows the calibration result for applying the projection theorem to estimate the parameters of the flood forecast model 


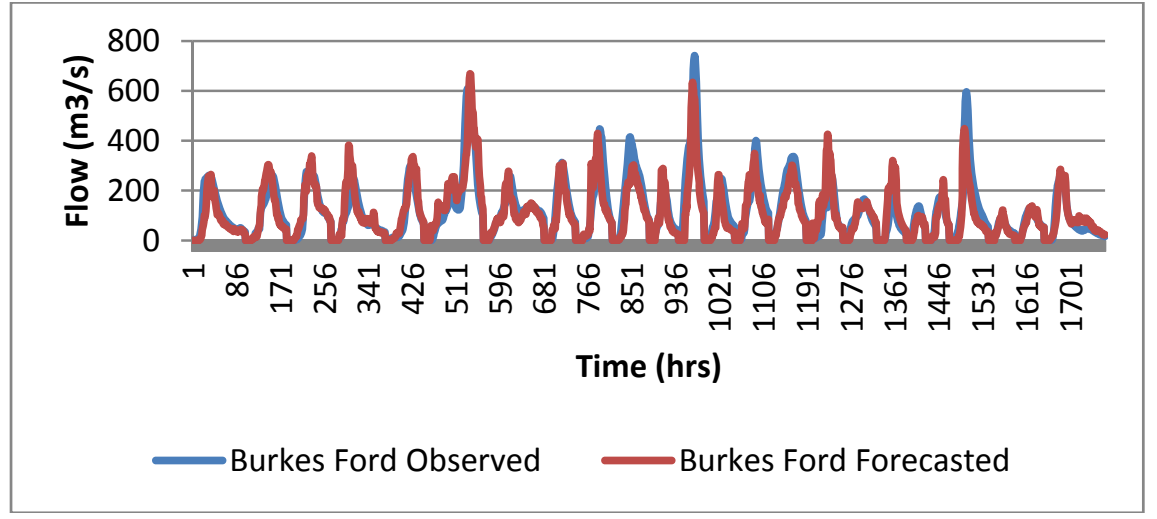

Figure 5: Results of the calibration for the forecast model.

Figures 6 and 7 presents the application of the derived forecast model to simulate the high flow events of June 2005 and April 2006, which were not included in the calibration process. In general, the model performed well, given the large catchment area of the Pomhaka River, and the high variability associated with the distribution of rainfall over the catchment. The model underestimated the peak flows of both events, but this is not expected to be the case all the time, as it is shown in the calibration that the model underestimates the peak flows for some events, and in other cases overestimates them.

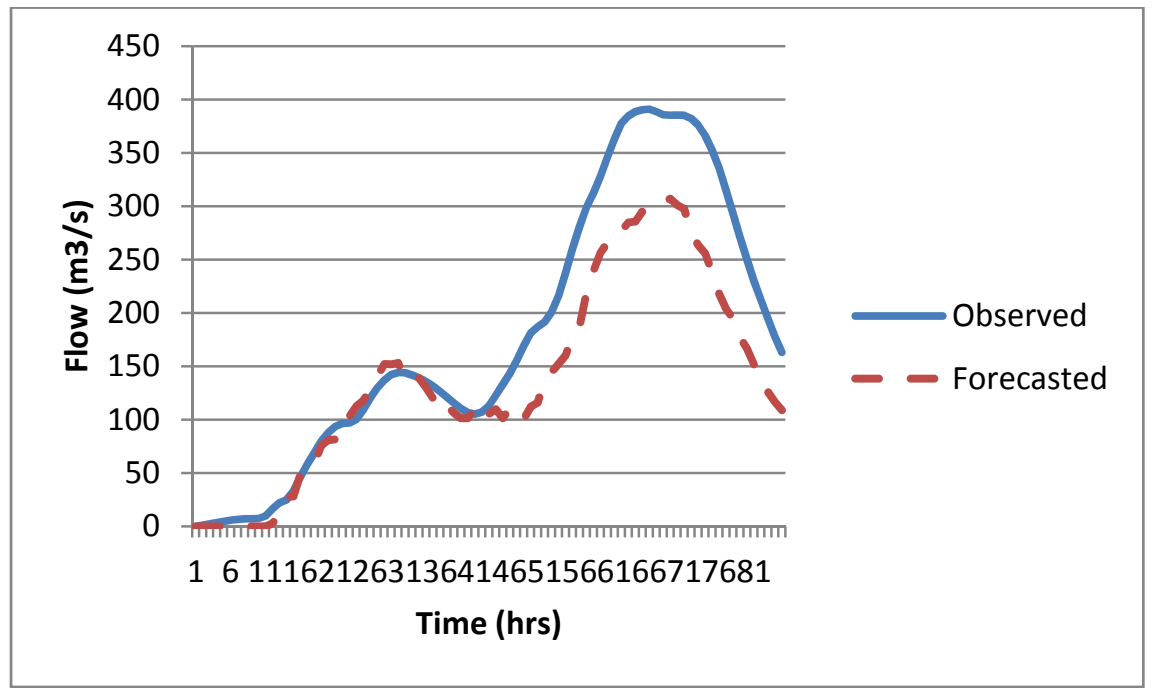

Figure 6: Model validation by application to the event of June 2005. 


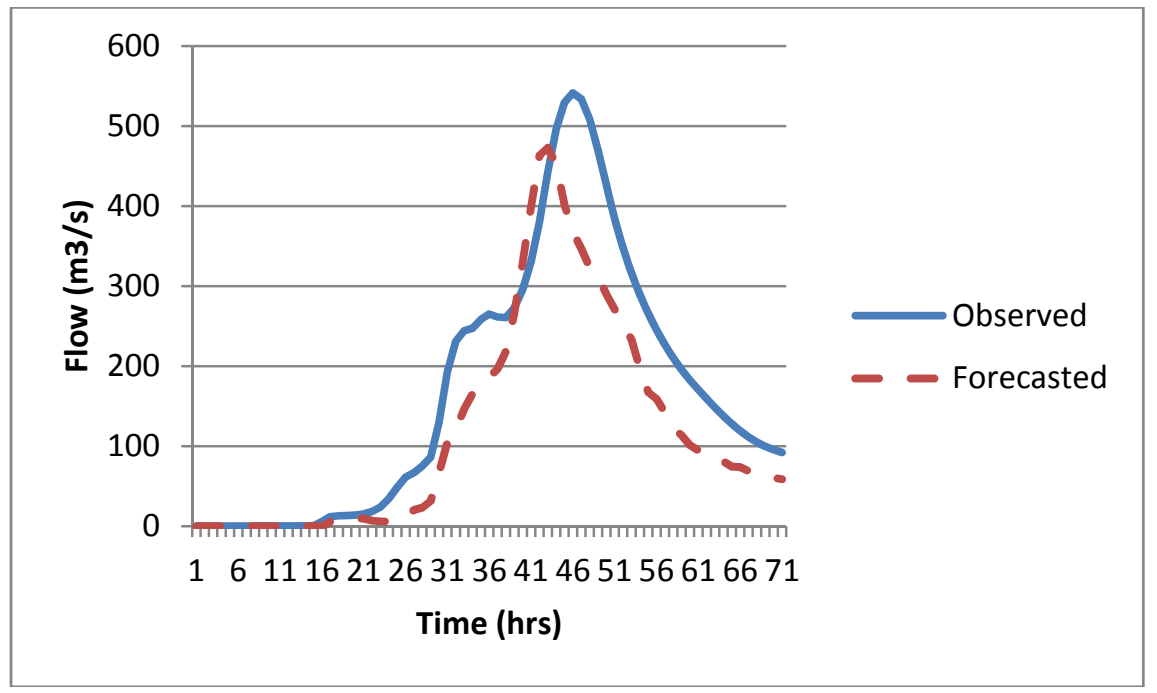

Figure 7: Model validation by application to the event of April 2006.

\section{Conclusion and recommendations}

Detailed analysis of available rainfall and flow events should be carried out to derive the best formula to relate effective rainfall "runoff" to observed rainfalls. The application of this approach produced more accurate runoff compared to the commonly applied approach of the US NRCS. The application of the projection theorem in Hilbert Space resulted in a suitable flood forecast model for the Pomahaka Catchment, where forecasted flows are forecasted based on current flows of the upstream tributaries and lagged hourly rainfalls at available rainfall sites. Once developed, this forecast model is easy to apply and doesn't require experienced hydrologist to use it. It is recommended to include current flows of the site to forecast in the modelling process, and to investigate the nonlinearity of the relationship for the projection of the flows onto other hydrologic variables.

\section{References}

[1] McSaveney, E., Floods - New Zealand's number one hazard, Te Ara - the Encyclopedia of New Zealand, updated 2 March 2009.

[2] Mohssen, M. Flood Forecasting of River Flows. 2014 Water Symposium, joint conference for the NZ Hydrological Society, NZ Freshwater Sciences Society and IPENZ Rivers Group, Blenheim, NZ.

[3] Mohssen, M. A New Approach for flood forecasting of River Flows. Flood recovery innovation and response IV. 18/06/2014, Poznan, Poland.

[4] Mohssen, M., A Multivariate Model for Flood Forecasting of Lake Levels. Int. J. of Safety and Security Eng., 3(2), pp. 141-152, 2013. 
[5] Mohssen, M. and Goldsmith, M., Flood Forecasting of Lake Levels: A New Concept. Int. J. of Safety and Security Eng., 1(4), pp. 363-375, 2011.

[6] Moore R J and Bell V A, Comparison of Rainfall-Runoff Models for Flood Forecasting, Part 1: Literature Review of Models. UK Environmental Agency R\&D Technical Report W241, 2001.

[7] Bell et al., Comparison of Rainfall-Runoff Models for Flood Forecasting, Part 2: Calibration and Evaluation of Models. UK Environmental Agency R\&D Technical Report W242, 2001.

[8] Demeritt D., H. Cloke, F. Pappenberger, J. Thielen, J. Bartholmes \& Maria-Helena Ramoset, Ensemble predictions and perceptions of risk, uncertainty, and error in flood forecasting, Environmental Hazards, vol 7, pp. 115-127, 2007.

[9] Jasper, K., J. Gurtz \& H. Lang, Advanced flood forecasting in Alpine watersheds by coupling meteorological observations and forecasts with a distributed hydrological model, Elsevier, Journal of Hydrology, 267, pp. 40-52, 2002.

[10] Tiwari, M. K., C. Chatterjee, Development of an accurate and reliable hourly flood forecasting model using wavelet-bootstrap-ANN (WBANN) hybrid approach, Elsevier, Journal of Hydrology, 394, pp. 458-470, 2010.

[11] Latt, Z. Z., H. Wittenberg, Improving flood forecasting in a develping country: a comparison study of stepwise multiple linear regression and artificial neural network, Water Resource Manage, 28:2109-2128, 2014.

[12] Bye, P. \& M. Horner, Easter 1998 Floods Report by the Independent Review Team to the Board of the Environmental Agency, vol. 1, Environmental Agency, Bristol, 1998.

[13] Datta, S., CWC failed to forecast, alert about floods, DNA, New Delhi, June 26, 2013.

[14] Chow, V.T., D. R. Maidment, L.W. Mays, 1988. Surface Water, sections 5.1-5.5 in "Applied Hydrology", McGraw Hill, Inc, NY, USA, pp. 127$155,1988$.

[15] Maidment, D.R., Hand Book of Hydrology, McGraw-Hill, Inc., pp. 9.219.22, 1993.

[16] Brockwell, P. J. \& R. A. Davis., Time Series: Theory and Methods, Springer-Verlag New York Inc., pp. 46-51, 1991. 